\title{
ASPEKTE EN TOEPASSING VAN DIE PASTORALE GESPREK
}

\section{DR. A. J. SMUTS}

Wanneer die pastorale sorg onder bespreking kom, is die pastorale gesprek een van die voor die hand liggende temas. Dit was nie altyd die geval nie, maar verskeie faktore het meegewerk om die belangstelling in hierdie onderwerp sterk te laat toeneem. Enkele daarvan is die volgende:

In die eerste plek staan ons voor die feit dat die gesprek aan belangrikheid gewen het na mate ander middele waarvan die kerk gebruik mak minder vanselfsprekend en meer problematies word. As gevolg van die proses van sekularisasie wat stilweg voortgaan, blyk dat die prediking deur talle nie meer gehoor en verstaan word nie. Die liturgie van die kerk het vir baie 'n vreemde, niksseggende reeks handelinge en woorde geword. Waar hulle nog deur die kategese bereik word, geskied dit dikwels op 'n stadium in hul lewens wanneer die werklike probleme nog nie uitgekristalliseer het nie. In hierdie situasie wen die pastorale gesprek aan belangrikheid.

Tweedens word klagtes omtrent die wyse waarop die pastorale gesprek gevoer word, dikwels verneem. „Die geldinsamelaardiaken het die herderdiaken vervang. Die nagmaalaankondigerouderling het die herder-ouderling vervang. Die kwartier-leesen-bid-predikant het die herder-predikant vervang," kla W. J. de Klerk. ${ }^{1}$ ) Met verwysing na L. Wagenaar en G. B. Wurth sê G. J. Kotzé: „Die pastoraat het ontaard in 'n outoritatiewe monoloog, 'n preek in sakformaat. Dit het 'n herhaalde klein erediens met 'n swyende gesin of enkeling geword. Die kerk het oorwegend preekkerk geword."2) In die lig van hierdie en soortgelyke verskynsels word dikwels gepraat van 'n devaluasie van die pastorale gesprek. Die vraag is egter of die situasie in die verlede veel gunstiger was. By die lees van Biesterveld se geskiedenis van die huisbesoek ${ }^{3}$ ) ontstaan die vraag of die gesprek ooit werklik tot

1) W. J. DE KLERK, Wending? Vernuwingsgesprekke oor die Gereformeerde Kerkpraktyk. Potchefstroom: Pro Rege, 1964, p. 82.

2) G. J. KOTZÉ, Die mensheskouing van die client-centered Amerikaanse pastoraal in die lig van die Bybelse gegewens en sy betekenis vir die pastorale denke. Ongepubliseerde proefskrif, P.U. vir C.H.O., 1970 , p. 267.

3) P. BIESTERVELD, Het Huisbezoek. Kampen: J. H. Kok, 1908 (2de druk). 
sy reg gekom het en of die verskynsels wat tans kommer wek, nie maar 'n voortsetting van 'n ou patroon is nie. Miskien kan ons eerder praat van 'n revaluasie van die pastorale gesprek. Oral merk ons onrus en besinning daaroor - oor hoe dit gevoer moet word, watter foute vermy moet word, hoe die kuns van gespreksvoering aangeleer kan word, ens. Soos nooit in die verlede nie is daar 'n bewuswording merkbaar van die geweldige moontlikhede wat in die pastorale gesprek skuil, maar ook van die probleme daaraan verbonde, waarvan ons vroeër geen vermoede gehad het nie. Die besef van die onvervangbare betekenis van die pastorale gesprek gaan gepaard met 'n groeiende besef dat meer deskundigheid vereis word as die predikant sy plek wil behou in die geledere van die groeiende aantal persone wat die helpende gesprek beoefen.

'n Derde faktor van betekenis is die nuwere ontwikkelinge op die terrein van die sielkunde, wat 'n diepgaande invloed op die bestudering en beoefening van die pastorale sorg gehad het. Gedurende die afgelope aantal jare het die sielkunde, wat hom vroeër veral besig gehou het met onderwerpe soos die sg. sielsfunksies van die enkeling, meteens die mens as medemens ontdek. Gevolglik word steeds meer aandag geskenk aan die mens-inverhouding. 'n Hele nuwe veld van wetenskap, kommunikasiekunde, is trouens besig om te ontstaan. Dit was egter veral die psigoterapie wat begin vra het na wat presies gebeur wanneer mense in 'n gespreksverhouding met mekaar verkeer. Hierdie studies is met vrug gebruik in die bestudering van die pastorale gesprek.

'n Vierde en laaste rede waarop ons wil wys, waarom die pastor tans gedwing word om hom duidelike rekenskap te gee van sy pastorale gespreksvoering, is geleë in die ingrypende veranderinge in die verwagtingspatrone waardeur ons tyd gekenmerk word. Terwyl dit vroeër so was dat die predikant vir meeste van sy gemeentelede - en vir homself - 'n taamlik duidelike figuur was, is dit nie vandag meer vanselfsprekend die geval nie: Vroeër was dit vir die predikant geen probleem om te weet wat sy mense van hom verwag, hoe hy as predikant moes optree en hoe hy met mense behoort te praat nie, want dit was alles daar in duidelikomskrewe rolverwagtinge. Omdat hierdie rolverwagtinge egter vervaag of verander het, is dit vandag van veel groter belang dat die pastor vir homself in sy gespreksvoering van oomblik tot oomblik sal rekenskap gee, van wat besig is om plaas te vind - of sy woorde "gehoor" word soos hy bedoel dat hulle gehoor sal word, of daar weerstande en struikelblokke aanwesig is wat die ingang van sy boodskap in die 
weg staan en of hy en die persoon met wie hy in gesprek verkeer inderdaad dieselfde taal praat in die sin dat hulle dieselfde betekenisse heg aan die woorde wat gebesig word. Hierdie situasie word nog moeiliker as die pastor geen duidelike beeld van sy eie identiteit het nie.

As gevolg van hierdie en soortgelyke omstandighede het die pastorale sorg sterker op die voorgrond getree en is veral in toenemende mate aandag geskenk aan die pastorale gesprek. In 'n sekere $\sin$ is die pastorale sorg dus nog 'n jong wetenskap. Netsoos ander vakgebiede van die teologie bevind hy hom egter tans in 'n tydperk van snelle en ingrypende verandering, waar dinge byna oornag kan verander. Terwyl nog geworstel word om te kom tot prinsipiële insigte en teologiese formulering, word alreeds weer kritiese vrae aan sy adres gerig van die kant van diegene wat meen dat die pastorale sorg soos ons dit ken eintlik reeds aan die verlede behoort, omdat in ons tyd nie meer die enkeling nie, maar die gemeenskapstrukture eintlik die voorwerp van bearbeiding deur die kerk behoort te wees. ${ }^{4}$ ) Uit die maalkolk van gedagtes en botsende menings, te midde van veel verwarring en stemme wat mekaar weerspreek, is 'n eietydse pastorale sorg en pastorale teologie egter stadig maar seker besig om vorm aan te neem. Sprekend hiervan is die titel van 'n boek wat onlangs verskyn het: „The New Shape of Pastoral Theology."5)

'n Studie van die pastorale gesprek kan van meer as een kant onderneem word. McGowan en Schmidt maak êrens die interessante opmerking dat sekere fases, wat in 'n bepaalde volgorde op mekaar volg, in die ontwikkelingsgang van enige beroep onderskei kan word..$^{6}$ ) Aan die begin word veral klem gelê op die praktiese aspekte: vraagstukke van tegniek staan op die voorgrond en die publikasies wat verskyn is vol voorskrifte oor hoe om op die regte wyse op te tree. 'n Tweede fase breek aan wanneer die aandag verskuif na die vraagstukke i.v.m. opleiding. Die derde fase gaan verder en dieper. Dit word bereik wanneer besinning begin plaasvind oor die filosofiese grondslae van die beroep. Dit is nie moeilik om dieselfde drie tendense te ontdek in die bestudering van die pastorale gespreksvoering nie, hoewel hulle nie altyd so noukeurig van mekaar afgebaken kan word nie.

4) Vgl. bv. W. E. Hulme, "Concern for corporate structures or care for the individual," Journal of Pastoral Care, Sept. 1969.

5) W. B. OGLESBY, JR. (Ed.), The New Shape of Pastoral Theology, Essays in honor of Seward Hiltner. Nashville/New York: Abingdon, 1969.

6) J. F. McGOWAN \& L. D. SCHMIDT, Counseling: Readings in Theory and Practice. New York: Holt, Rinehart \& Winston, 1962, p. 96. 
Die eerste fase word verteenwoordig deur 'n groot aantal geskrifte wat raadgewinge bevat oor hoe pastorale gesprekke gevoer behoort te word. Hierdie publikasies is gewoonlik van praktiese opset, vol voorbeelde en soms ook praktiese oefeninge. (Bv. Hiltner ${ }^{7}$ ), Faber en van der Schoot $\left.^{8}\right)$, Hostie ${ }^{9}$ ), Rensch $\left.{ }^{10}\right)$, de Bont $^{11}$ ) e.a.). Die tweede stadium bring ons op die terrein van die kliniese pastorale vorming en die opleiding in die pastorale sorg. Uit meerdere geskrifte kan hier twee voorbeelde genoem word: T. W. Klink se deeglike uiteensetting van supervisie as onderdeel van die teologiese opleiding ${ }^{12}$ ) en W. Zijlstra se proefskrif. ${ }^{23}$ ) Die derde stadium van die ontwikkelingsproses word verteenwoordig deur geskrifte wat 'n brug probeer slaan tussen die praktyk en die beginsels en die teologiese implikasies probeer uitwerk. (Bv. Thurneysen ${ }^{14}$ ), Oden ${ }^{15}$ ), Browning ${ }^{16}$ ) en artikels in die bundel onder redaksie van Oglesby. $\left.{ }^{17}\right)$ ).

In die formulering van die onderwerp - wat nie van die skrywer afkomstig is nie - word tereg klem gelê op twee sake: aspekte en toepassings. Ons sou dit ook kon aandui as die dinamiek en inhoud van die pastorale gesprek. Dit is die dubbele probleem waarvoor die pastor telkens te staan kom wanneer hy 'n pastorale gesprek moet voer: die hoe en die wat daarvan. By die vraag na die hoe gaan dit veral om die dinamiese verloop van so 'n gesprek. Sake soos klemverskuiwings, die rol van gevoelens, die betekenis van verdedigingsmeganismes, ens. kom hierby ter sprake. Verder moet die vraag egter ook gestel word na die wat

?) S. HILTNER: Pastoral Counseling. New York/Nashville: Abingdon, 1949. IBID. The Counselor in Counseling. New York/Nashville: Abing don, 1952 (3de druk).

8) H. FABER \& E. VAN DER SCHOOT, Het Pastorale Gesprek. Utrecht: Bijleveld, 1962.

8) R. HOSTLE, De Pastorale Dialoog. Brugge/Utrecht: Desclee de Brouwer, 1963.

10) A. RENSCH, Das Seelsorgerliche Gespnäch, Psychologische Hinweise zur Methode und Haltung. Göttingen: Vandenhoeck \& Ruprecht, 1963.

11) W. DE BONT, Vuistregels voor het Pastorale Gesprek. Hilversum: N. V. Gooi \& Sticht, 1967.

12) T. W. KLINK, "Supervision" in: C. R. FEILDING, Education for Ministry. Dayton, Ohio: American Association of Theological Schools, 1966.

13) W. ZIJLSTRA, Klinisch Pastorale Vorming, Een voorlopige analyse van het leer- en groepsproces van zeven cursussen. Assen: van Gorcum, 1969.

14) E. THURNEYSEN, Die Lehre von der Seelsorge. Zollikon-Zürich: Evangelischer Verlag, 1952. IBID., Seelsorge im Vollzug. Zürich: Evangelischer Verlag, 1968.

15) T. C. ODEN, Kerygma and Counseling. Philadelphia: Westminster Press, 1966. IBID., Contemparary Theology and Psychotherapy. Philadelphia: Westminster Press, 1967.

16) D. S. BROWNING, Atonement and Psychotherapy. Philadelphia: Westminster Press, 1966.

17) W. B. OGLESBY: Op.cit., 
van die gesprek - die inhoudelike sy daarvan. Terwyl ons nog by die aspekte in algemene terme kan praat oor die gesprek, stel die toepassings ons voor die konkrete eise van die praktyk, waar ons te doen kry met mense in 'n groot verskeidenheid situasies wat aan die pastor telkens nuwe eise stel.

By die bestudering van die pastorale gesprek moet sowel die dinamiek as die inhoud aandag ontvang. In die taal van Kant sou ons kon sê dat dinamiek sonder inhoud leeg is, maar slegs inhoud sonder aandag aan die dinamiek is blind. So 'n onderskeiding is natuurlik altyd enigsins kunsmatig. In die werklikheid vind ons immers geen gsprek waarby dit slegs om inhoud gaan en waarin daar geen dinamiese proses afspeel nie. Netso ondenkbaar is dit dat enige gesprek - allermins 'n pastorale gesprek - bloot 'n dinamiese gebeure sal wees sonder oordrag van inhoud van een mens na die ander. In werklikheid is dit dus 'n formele onderskeid wat ons maak. Tog het dit sy waarde, want dit open ons oë vir'n moontlike eensydigheid. In die verlede is die aandag nl. veral gerig op die inhoudelike aspekte van die pastorale gesprek, terwyl die dinamiek daarvan buite beskouing gebly het. In ons tyd het die pendulum weer baie ver in die ander rigting geswaai. Die ontdekking is gemaak dat in so 'n gesprek veel meer plaasvind as die oordrag van 'n aantal waarhede op intellektuele vlak. Gevolglik word nie meer in die eerste plek gevra: "Wat is gesê?" nie, maar „Wat het gebeur?" Deur die onderskeiding tussen dinamiek en inhoud word ons daaraan herinner dat albei hierdie vrae wettige en nodige vrae is.

\section{DINAMIEK}

In ons bespreking van die dinamiek van die pastorale gesprek kies ons een probleem waarby ons wil stilstaan. Moontlik kan hierdie saak beskou word as die kernprobleem in die besinning oor die pastorale gespreksvoering. Dit gaan om die spanning tussen die aspekte van luister en spreke in die gesprek. In die pastorale gesprek neem dit die vorm aan van 'n spanning tussen die aspekte van beraad en verkondiging.

Wat is die posisie wanneer ' $n$ pastor gaan sit om met iemand 'n pastorale gesprek te voer? Dan moet hy van twee dinge duidelik bewus wees. In die eerste plek moet hy weet dat hy die draer en verkondiger is van 'n Woord. Hierdie Woord is veel meer as die blote woord van 'n mens, en voor hierdie Woord is alle menslike woorde en opinies eintlik onbelangrik. Wanneer hierdie gesaghebbende Woord klink - „So spreek die Here!" - bly daar vir die mens eintlik net een ding oor om te doen: Hy moet die hand op die mond lê en een en al oor wees, terwyl hy daarna 
Juister. Dit is die wonderlike voorreg, maar ook die huiweringwekkende verantwoordelikheid van die pastor, as dienaar van die goddelike Woord, om hierdie Woord in die wêreld te laat klink en weerklink.

Maar nou is daar ook die ander kant van die saak. Veral in ons tyd kom die pastor meer en meer tot die ontdekking dat hy nie weet hoe om daardie boodskap so te bring dat dit werklik deur die ander persoon gehoor en verstaan word as hy nie begin deur eers lank en aandagtig na hom te luister nie. Ja, wat meer is: hierdie luister na die ander is nie bloot 'n voorstadium, wat so gou as moontlik afgehandel moet word, sodat hy die woord kan neem nie. Dit het waarde op sigself. Die mens wat iemand vind teenoor wie hy sy hele hart kan uitspreek, ervaar dikwels dat hy in hierdie proses van spreek en na-geluister-word self verander. Omdat dit waar is, verskyn daar tans geen boek oor die pastorale gesprek waarin nie op talle bladsye en in vele toonaarde beklemtoon word dat die pastor nie net 'n sprekende mond nie, maar ook 'n luisterende oor moet hê en 'n meester moet word in die kuns van goed te kan luister. Ook in die kliniese pastorale vorming gaan dit hoofsaaklik daarom om fyn te leer luister. Meer as een deelnemer aan hierdie vorm van opleiding moes al tot die pynlik maar heilsame ontdekking kom dat sy goedbedoelde Woordverkondiging die ander persoon nie bereik nie, omdat hy nagelaat het om eers goed na hom te luister en die stille boodskap, wat miskien agter sy woorde verskuil was, te verneem.

Hierdie spanning is prinsipieel onoplosbaar. Sodra die pastor die een kant van die saak laat val ten koste van die ander gaan iets verlore. Dan ontaard die pastorale gesprek in of 'n alleenspraak of 'n bloot simpatieke luister na die ander, waarin die gesaghebbende Woord ontbreek. Die kreatiewe spanning tussen hierdie twee elemente moet altyd gehandhaaf word en oor die plek wat elkeen in die gesprek moet inneem, sal die pastor in elke geval ' $n$ beslissing moet neem na die eis van omstandighede.

Nou is dit besonder interessant om daarop te let dat elkeen van hierdie elemente gestalte gevind het in 'n besondere vorm van pastorale sorg. In die pastorale sorg van die kerk kan verskillende lyne of tradisies onderskei word en die twee hoofrigtings kan juis onderskei word aan die verskil in aksent wat hierdie saak betref.

\section{Die Lyn van die Tradisionele Pastorale Sorg}

- Die tradisionele reformatoriese omskrywing van die pastorale sorg lui dat dit die verkondiging van die Woord van God aan die enkeling is. W. J. de Klerk noem die name van 'n hele aantal 
skrywers by wie hierdie opvatting gevind word. ${ }^{18}$ ) Aan hierdie erfenis moet ons vashou. In die pastorale gesprek moet die gesaghebbende Woord aan die woord kom. Tog mag ons nie ons oë sluit vir die eensydigheid van hierdie benadering of vir die gevare wat aan 'n verkeerde toepassing daarvan verbonde is nie. Die belangrikste gevaar is dat die pastor vanuit sy voonopgesette raamwerk die ander toespreek en nooit by sy werklike behoeftes en probleme uitkom nie omdat hy nie die moeite gedoen het om eers goed na hom te luister nie. Dit lei tot 'n wêreldvreemde pastoraat waarvan mense teleurgesteld wegdraai.

Selfs die belangrike werk van Thurneysen, wat veel klem lê op die noodsaaklikheid daarvan dat die pastorale sorg in die vorm van 'n gesprek sal plaasvind, ontkom nie aan hierdie gevaar nie. ${ }^{19}$ ) Hy gaan daarvan uit dat in die pastorale gesprek 'n breuk merkbaar sal word, waar die Woord van God, as „vreemde Woord" gehoor word.

E. van der Schoot is - o.i. tereg - van oordeel dat 'n benadering waarin die klem eensydig op die verkondigende element val, wel in die verlede tot groot seën was, maar dat dit in ons tyd nie meer deug nie. In die huidige wêreld blyk dit ten aansien van steeds meer mense volstrek onvrugbaar te wees. ${ }^{20}$ )

Die Lyn van die „Pastoral Counseling”-beweging

Terwyl die tradisionele benadering hom kan beroep op 'n lang tradisie, is die verskynsel van „pastoral counseling” of pastorale beraad van redelik onlangse oorsprong. Gedurende die afgelope twee dekades het egter geblyk dat hierdie gedagterigting, wat uit Amerika afkomstig is, so dinamies en invloedryk is dat dit sy invloed wêreldwyd laat geld. ${ }^{21}$ ) Dit is noodsaaklik dat ons vir onsself duidelik rekenskap sal gee omtrent wat hierdie rigting bedoel, met watter elemente daarin ons ons kan vereenselwig en waar ons vraagtekens moet plaas.

Om 'n oorsig oor die groot aantal publikasies wat oor die jare verskyn het, te verkry, is geen eenvoudige saak nie. 'n Oorsig en beoordeling van hierdie beweging is egter deur L. G.

18) W. J. DE KLERK, Op.cit., p. 160. IBID., Rousmart, Die pastorale sorg oor bedroefdes na die oorlye van 'n dierbare. Johannesburg: De Jong, 1968 , p. 243.

19) E. THURNEYSEN, Die Lehre von der Seelsorge.

20) E. VAN DER SCHOOT, Hoofdstukken uit de Pastorale Psychologic. Utrecht: Bijleveld, 1959, p. 31.

21) Vgl. bv. GRAEME M. GRIFFIN, „Pastoral theology and pastoral care overseas," in: W. B. OGLESBY, Op.cit. 
Wagenaar ${ }^{22}$ ) gegee en meer onlangs ook deur Dietrich Stollberg, wat dit heeltemal tereg tipeer as ,terapeutiese sielsorg." ${ }^{23}$ )

Ons kan die „pastoral counseling” eers reg verstaan en beoordeel as ons verstaan wat dit bedoel om te wees. Uit die literatuur is duidelik dat dit nie eenvoudig 'n ,Amerikaanse wyse van pastoraat" is nie. Daarom is dit ook verkeerd om die ,pastoral counseling" en die tradisionele vorm van pastorale sorg eenvoudig teenoor mekaar te stel en die een vanuit die ander te kritiseer.

Clinebell verduidelik die saak soos volg: Die kerk se taak in die wêreld word tradisioneel as 'n drievoudige gesien: Kerugma, koinonia en diakonia. Pastorale beraad is primêr 'n uiting van die diakonia, d.w.s. dit is ' $n$ implementering van die geloof in liefdevolle diens aan die naaste. Hoewel hy toegee dat die ander twee elemente ook 'n rol kan speel, staan die diakonale duidelik op die voorgrond. ${ }^{24}$ ) Reeds in 1949 het Hiltner uitdrukking aan hierdie siening gegee in sy definisie van wat "pastoral counseling" is, toe hy geskryf het: „Broadly speaking, the special aim of pastoral counseling may be stated as the attempt by a pastor to help people help themselves through the process of gaining understanding of their inner conflicts." ${ }^{25}$ ) Hoewel sedertdien dikwels stemme opgegaan het teen die twyfelagtige teologiese verondersetllinge waarop hierdie vroeë formuleringe van Hiltner berus. en gepleit is vir dieper teologiese besinning oor die werklike grondslae van die hulp wat gebied word, het aan die basiese uitgangspunt van die ,pastoral counseling" nie veel verander nie. Dit bly hulpverlening t.o.v. lewensprobleme, 'n sielkundig-verantwoorde wyse van omgang tussen mense waardeur' $n$ innerlike groeiproses gestimuleer word en hulle gehelp word om hulself te help. Die pastorale element is daarin geleë dat die hulp deur 'n pastor verleen word, maar verwys nie noodwendig na die aard van die hulpverlening self nie.

In die „pastoral counseling" word dikwels - gewoonlik in 'n laaste hoofstuk van 'n boek oor hierdie onderwerp - verwys na wat genoem word „religious resources" waaroor die pastor be-

22) L. G. WAgenaAR, Over een Amerikaanse Wijze van Pastoraat, Beschrijving en beoordeling van het pastoral counseling. 's Gravenhage: Boekencentrum, 1959.

23) D. STOLLBERG, Therapeutische Seelsorge, Die Amerikanische Seelsorgebewegung, Darstellung und Kritik, mit einer Dokumentation. München: Chr. Kaiser Verlag, 1969.

24) H. J. CLINEBELL. Basic Types of Pastoral Counseling. Nashville/New York: Abingdon, 1966 .

25) S. HILTNER, Pastoral Counseling. 
skik in die uitvoering van sy taak, nl. die Bybel, gebed, die Christelike gemeenskap, e.d.m., maar in strenge sin behoort dit nie tot die wese van die "pastoral counseling" self nie.

\section{Is 'n Sintese moontlik?}

Hierdie vraag sou ons bevestigend wou beantwoord.

Die tradisionele opvatting van die pastorale sorg as Woordverkondiging gaan uit van die einddoel. In die praktyk sal hierdie vorm van pastorale sorg tog nooit uitsluitlik uit Woordverkondiging bestaan nie. Elke pastor moet tog, om tot die element van Woordverkondiging te kom, eers 'n aanloop neem. Voordat hy die Bybel oopslaan om oor te gaan tot Bybellesing en verkondiging, sal hy tog iets te wete probeer kom omtrent die persoon of persone met wie hy te doen het en sal hy een of ander aanknopingspunt probeer ontdek.

Aan die ander kant lê die „pastoral counseling”-benadering veral die klem op die weg wat tot hierdie einddoel lei. Dit is wel moontlik dat sommige hierdie weg so lank sal maak dat hulle die einddoel nooit bereik nie. Ander weer gaan uit van die gedagte dat die diens van die Kerk in die wêreld sonder meer reeds implisiete verkondiging is, m.a.w. die weg is reeds 'n doel op sigself sonder dat godsdienstige woorde uitdruklik gespreek hoef te word. Ons wil graag toegee dat daar pastorale gesprekke is waar dit waar is, terwyl daar ook lang gedeeltes van 'n reeks pastorale gesprekke is waarin geen uitdruklike verkondiging hoef voor te kom nie. Tog neem dit alles nie die waarheid van die stelling weg nie dat die „pastoral counseling” 'n element van die pas torale gespreksvoering beklemtoon waaraan in die verlede te min aandag geskenk is, maar dat so 'n gesprek eers sy voltooiing bereik wanneer daar op een of ander wyse verkondiging van die evangelie plaasgevind het.

O.i. moet in die volledige pastorale gesprek dus twee elemente aanwesig wees: 'n element van begeleiding en 'n element van leiding. Terwyl hy die ander persoon begelei, wandel die pastor as't ware met hom mee op die paaie van sy keuse. Terwyl die pastor diep en aandagtig luister en daarby nie slegs op die woorde van die ander let nie, maar ook op sy gevoelsuitinge, verken hulle saam die probleme, die vreugdes en die moontlikhede van die situasie van die ander persoon. Die taak van begeleiding stel aan die pastor hoë eise. Dit is nie slegs tydwordend, sodat dit soms oor meer as een gesprek versprei moet word nie, maar vereis ook vaardigheid in sake soos empaties te kan luister en die gevoelens van die ander suiwer op te vang en te reflekteer. Skoling is hierby 'n vereiste. 
Die element van begeleiding is so belangrik omdat daardeur 'n verhouding tussen die deelnemers aan die gesprek gebou word, wat die noodsaaklike vereiste vir vrugbare verkondiging is. Tereg sê Clinebell in hierdie verband: „As the parishioner senses, even vaguely, that the minister is really trying to listen deeply and to relate fully, a tiny fragile nexus as delicate as a spider web will begin to connect his aloneness with the minister's aloneness. This is the first, vital strand of what will become a sturdy bridge connecting the island of awareness of two human beings. This bridge is called rapport." ${ }^{26}$ )

Hierby eindig dit egter nie. Naas die begeleiding mag in die pastorale gesprek met vrymoedigheid gebruik gemaak word van die element van leiding. Wat die inhoud van hierdie leiding sal wees, is hier nie ter sake nie. Dit kan vermaning, lering, bemoediging, vertroosting of een van talle ander dinge wees. Wat egter wel belangrik is, is dat die deelnemers aan die gesprek, nadat hulle saam gekyk het na die omstandighede, ook daar sal kom waar hulle saam sal luister na die Woord van God wat hulle juis in hierdie omstandighede aanspreek. Hierby val die nadruk op die woord "saam". Die ondervinding leer immers dat dit dikwels in 'n pastorale gesprek wat so benader word, voorkom dat dit nie die pastor is nie, maar die ander persoon wat die godsdienstige implikasie van die saak onder bespreking raaksien en aan die orde stel.

Een laaste vraag: Moet ons ons die verloop van die pastorale gesprek dus in terme van fases voorstel, waarby die beraad, waarin die pastor hoofsaaklik luisteraar is, as eerste fase aan die verkondiging, waarby hy hoofsaaklik aan die woord is, voorafgaan? So 'n indeling sou nie 'n getroue weergawe wees van wat in 'n pastorale gesprek plaasvind nie. Albei elemente is deurgaans aanwesig. Hoogstens kan daar sprake wees van 'n klemverskuiwing tydens die verloop van die gesprek, sodat die luisterende aspek in die optrede van die pastor in die eerste gedeelte op die voorgrond staan, maar later meer en meer plek maak vir die verkondigende aspek.

\section{INHOUD}

Waaroor behoort in 'n pastorale gesprek gepraat te word? Hierop moet die antwoord lui: Oor enigiets. Enige saak kan die onderwerp van so 'n gesprek vorm. Die toepassingsveld van die pastorale gesprek is dus so wyd as die lewe self. Dit kan wissel van die mees alledaagse tot die mees verhewe en diepsinnige temas. Om te kwalifiseer vir 'n pastorale gesprek, moet egter aan

26) H. J. CLINEBELL, Op.cit., p. 60 . 
een vereiste voldoen word: op een of ander wyse moet die lig van die evangelie oor die onderwerp van bespreking val. Elders het skrywer hiervan dit soos volg geformuleer: „'n Pastorale gesprek word gevoer wanneer vanuit enige saak wat ter sprake kom, deurgedring word tot die persoonlike betekenis wat dit vir die persoon het, en die gesprek dan nie bly vassteek in 'n uitsiglose bespreking op menslike vlak nie, maar bevrydende lig van die evangelie daaroor val." ${ }^{27}$ )

Kan 'n pastorale gesprek bv. oor die weer gevoer word? Sonder enige twyfel! Dit is goed denkbaar dat 'n pastor vanuit 'n gesprek oor die weer kan deurdring tot sake soos die invloed van langdurige droogte op die geloofslewe van die boer, probleme rondom reënmakery en biddae om reën en op 'n nog dieper vlak die verhouding tussen die natuurwette en die voorsienigheid van God. Ds. Overduin vertel in een van sy boeke van sy ervaringe as gevangene tydens die Tweede Wêreldoorlog. Dit was hom nie toegestaan om te preek nie, maar by 'n sekere geleentheid het hy toestemming gevra om sy medegevangenes te mag toespreek. Toe hy moes sê waaroor hy hulle wou toespreek, het hy geantwoord dat hy 'n lesing oor 'n vliegtuig wou hou. Sonder enige moeite het hy spoedig by die pastorale aspekte van sy onderwerp uitgekom en begin praat oor die mens wat in beheer van die vliegtuig is, met al sy menslike probleme - en waar die oplossing vir hierdie probleme gevind kan word.

'n Indeling van die toepassings van die pastorale gesprek sou dus hoogstens op praktiese grondslag kon geskied, met die oog daarop om te sistematiseer en feite te groepeer. Eers wanneer die toepaslike feite byeen gebring is, word dit moontlik om 'n oorsig te kry.

Dit het die verdere voordeel dat die besinning oor die pastorale gesprek daardeur aan die konkrete werklikheid gebind word. Wanneer slegs die proses van die gesprek bestudeer word, kan dit maklik gebeur dat dit by 'n teoretiese bespreking gelaat word. Die beste manier van bestudering van die pastorale gesprek bly trouens nog om dit te doen aan die hand van 'n konkrete gespreksvoorbeeld.

In die literatuur tref ons 'n groot verskeidenheid indelinge aan, waardeur die inhoud of toepassingsvelde van die pastorale gesprek afgebaken word. Gewoonlik word die verskillende lewensfases van die mens en verskillende probleemgebiede as fokuspunte gekies. In die „Successful Pastoral Counseling Series” het bv. verskillende deeltjies verskyn oor die pastorale sorg aan

27) A. J. SMUTS. Die Pastorale Gespreksvoering. Ongepubliseerde Proefskrif, U.P., 1970, p. 235. 
siekes en sterwendes, psigiatriese pasiënte, mense met huweliksprobleme, persone wat opgeroep is tot militêre diens, bejaardes, dwelmmiddelverslaafdes, ongehude moeders, ens.

'n Meer bevredigende indeling tref ons egter aan in die onlangse boek „Learning about Pastoral Care" deur C. F. Kemp..") In hierdie boek, wat as leerboek saamgestel is, gaan die skrywer van die gedagte uit dat die pastor in sy pastorale sorg met drie tipes situasies te doen kry:

(1) Krisissituasies. Hieronder val pastorale sorg aan siekes, bedroefdes en slagoffers van een of ander vorm van teëspoed.

(2) Langdurige of blywende situasies. Dit sluit in situasies wat lei tot pastorale sorg aan persone wat om een of ander rede huisgebonde is ,the shut-in, the home-bound"), bejaardes, invalides, die gesin van 'n vertraagde kind, e.d.m.

(3) Roetine-situasies wat lei tot gewone pastorale besoeke. Hieronder reken hy besoeke aan afgedwaaldes, onverskilliges, nuwe intrekkers, jonggetroude egpare, ens. Hoewel hy die gereelde huisbesoek (moontlik nie aan hom bekend nie) nie noem nie, sou dit ook hieronder ressorteer.

Vir Kemp vorm die pastorale sorg 'n onderdeel van 'n wyer begrip, wat hy aandui as die pastorale bediening. In die pastorale bediening van die predikant onderskei hy die volgende elemente: ${ }^{29}$ )

(1) „Pastoral care”.

(2) „Pastoral counseling” (Korttermyn- en langtermynberaad).

(3) „Religious guidance” (waaronder voorhuwelikse beraad, die verstrek van informasie, die gee van leiding t.o.v. beslissinge wat persone moet neem, ens. val).

(4) „Religious social service”. (Hieronder val praktiese hulpverlening van allerlei aard.)

(5) „Ministry of referral”.

(6) „Casual, informal, administrative contacts."

So gestel, dek die pastorale bediening feitlik die hele bediening van die predikant en is dit nodig om tot 'n nadere afgrensing te kom. Hy sonder dan ook enkele groepe uit as „,special

\footnotetext{
28) C. F. KEMP, Learning about Pastoral Care. Nashville/New York: Abingdon, 1970.

29) Ibid. pp. 38-39.
} 
areas of pastoral concern", waarmee die pastor dikwels in aanraking kom en waarby hy breedvoeriger stilstaan. Hierdie terreine van toepassing sluit dan die volgende in: ${ }^{30}$ )

(1) "A ministry to the sick".

(2) "A ministry to the sorrowing".

(3) "Counseling and care of families".

(4) "Vocational choice and adjustment."

(5) "The minister and mental health."

(6) "The pastor and the alcoholic."

(7) "A ministry to the handicapped."

(8) "The pastoral care of older persons."

(9) "The pastor and the underprivileged."

(10) "The pastor and the transient."

(11) "The pastor and the delinquent and criminal."

(12) "A ministry to the gifted and the retarded."

(13) "Counseling and guidance on religious problems."

By bostaande oorsig wil ons dit laat. Ons het slegs in voëlvlug 'n beeld probeer kry van die toepassingsmoontlikhede van die pastorale gesprek. Dit val buite die bestek van hierdie stuk om nadere aanwysings te probeer gee omtrent die wyse waarop die pastorale gesprek met bostaande tipes mense en in situasies van hierdie aard gevoer moet word.

\section{SLOTSOM}

Uit alles wat in die voorgaande gesê is ,moet ten slotte enkele gevolgtrekkinge gemaak word. Op drie sake wil ons die klem laat val.

In die eerste plek blyk die noodsaaklikheid daarvan al duideliker dat die pastor duidelikheid en vaardigheid in die pastorale gespreksvoering moet hê. Die duidelikheid verkry hy deur studie, die vaardigheid deur oefening - verkieslik onder supervisie. Hy moet 'n oog kry vir die verskillende elemente in die pastorale gesprek, faktore wat die voortgang van die gesprek kan bevorder of strem, die rol wat die gevoelsverhouding speel, e.d.m. In die opleiding van die pastor verdien die pastorale gespreksvoering ongetwyfeld 'n ruime mate van aandag.

Tweedens is dit duidelik dat die predikant wat in die gewone gemeentelike bediening arbei, in die gang van sy dagtaak met 'n groot verskeidenheid menslike probleme en situasies in aanraking kom. Dit is dus noodsaaklik dat hy toegerus sal wees met die nodige kennis om 'n positiewe bydrae te kan lewer. Terwyl die lewe steeds meer gekompliseerd word, kan dit nie verwag word

s0) Ihid., p. 131v. 
dat hy oor parate kennis omtrent alles en nog wat sal beskik nie. Wat egter wel verwag kan word, is dat hy gewillig sal wees om homself enigsins op hoogte te stel wanneer nodig. Daar is veel voor te sê dat die pastor nie noodwendig alles in een gesprek probeer afhandel nie, maar die eerste gesprek soms opvolg deur 'n korter of langer reeks gesprekke. Vir hom bring dit die voordeel mee dat dit hom in staat stel om oor die saak na te dink en indien nodig ook na te lees. Aan die ander kant sit dit by die persoon met wie die gesprekke gevoer word dikwels 'n proses aan die gang wat lei tot geleidelike maar ingrypende veranderinge.

In die derde plek bring die kategorisering van die verskillende toepassingsterreine van die pastorale gesprek opnuut die feit onder die aandag dat 'n mate van spesialisasie op die gebied van die pastorale sorg in ons tyd onvermydelik geword het. In die praktyk het die kerke reeds lankal getoon dat hulle hierdie feit aanvaar het. In steeds ruimer mate word gebruik gemaak van die dienste van predikante wat hulle ingewerk het in die probleme wat saamhang met die bearbeiding die jeug, van siekes en sterwendes, van alkoholiste, van mense met huweliksprobleme, van kerkvervreemdes en buitekerklikes, ens. Terwyl ons bewus is van die besware wat 'n suiwer kategoriale bediening aankleef, kan die noodwendigheid van spesialisasie as antwoord op die gekompliseerde probleme waarvoor die kerk in die moderne tyd te staan kom nie ontken word nie. Dit kan verwag word dat in die toekoms nog hoër eise gestel sal word en dat dus nog meer kundigheid en toewyding vereis sal word. 